\title{
Adenoid Cystic Carcinoma of the Sinonasal Tract: Two Cases Report
}

\author{
Mouna Bellakhdher, Maha Mejbri*, Wassim Kermani and Mohamed Abdelkefi \\ ENT Department, Farhat Hached Academic Hospital, Tunisia
}

*Corresponding author: Maha Mejbri, ENT Department, Farhat Hached Academic Hospital, Sousse, Tunisia

\begin{abstract}
Adenoid cystic carcinomas (ACC) of the sinonasal tract is a malignant neoplasm, characterized by slow and insidious growth. Thus, patients usually present in advanced stages. Clinical presentation is unspecific. Treatment is based on surgery followed by radiotherapy. Since the tumor spreads through perineural and hematological routes, delayed metastasis and local recurrence may occur several years after remission. In the present manuscript, we report the case of two patients who present with an ACC of the maxillary sinus diagnosed in an advanced stage. Orbital and cerebral involvement was objectified in one patient. Treatment consists in surgery. Post-operative radiotherapy was performed in one patient. He had a complete remission. Loco-regional recurrence occurred in the second patient. ACC is a particular entity among sinonasal cancers. Further studies are needed to define multimodal treatment including surgery, radiotherapy, and chemotherapy.
\end{abstract}

Keywords: Adenoid cystic carcinoma; sinonasal tract; surgery, radiotherapy

\section{Introduction}

Adenoid cystic carcinoma (ACC) of the sinonasal tract is a rare cancer that originates from salivary glands [1]. It is the most frequent malignancy in the maxillary sinus among non-squamous cell carcinomas [2]. Clinically, it presents as a slow growing and locally aggressive tumor with a tendency to local recurrence and late metastasis [3]. Through two cases report, we illustrate clinical, histological, and therapeutic characteristics of sinonasal ACC.

\section{Case Presentation}

\section{Case 1:}

A 50-year-old female patient, with no medical history, presented with right nasal obstruction, epistaxis and nasal discharge that appeared one year ago. Physical examination found a mass of the right nasal cavity. The neck was free from lymph nodes. The neurological and ophthalmological examination were normal. CT scan showed a $5 \mathrm{~cm}$ mass, occupying the right maxillary sinus (Figure 1). Tumor extended to the ethmoid and the right nasal cavity.
A biopsy of the lesion was performed. Histological examination (Figure 2) concluded to ACC with a cribriform type. No metastasis was found. Tumor was classified T3N0M0. Patient was operated on by Rouge-Denker technique. Post-operative radiotherapy was performed. Patient had regular clinical and radiological follow-up. No recurrence was noted during the 10 year-follow-up.

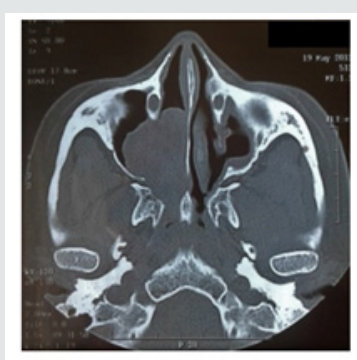

Figure 1: Axial CT scan showed a tumor of the right maxillary sinus. 


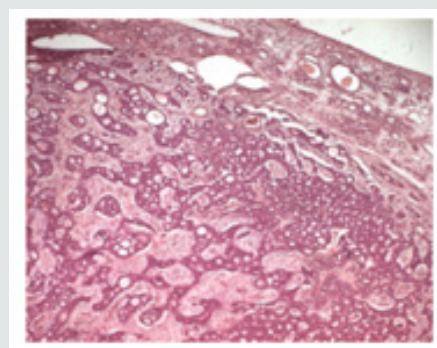

Figure 2: Histological examination showed a cribriform type of ACC.

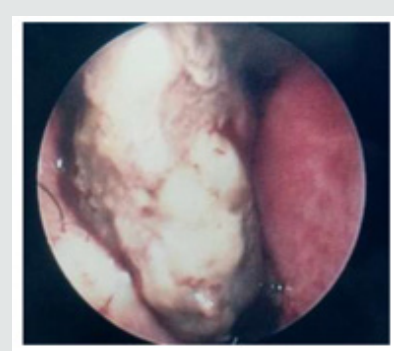

Figure 3: A bleeding mass occupying the left nasal cavity.

\section{Case 2:}

A 39-year-old male patient, presented with unilateral rhino logical symptoms (epistaxis, rhinorrhea, and nasal obstruction) evolving for 5 months. At the physical examination, we found a nasal deformity and a bleeding mass of the left nasal cavity (Figure 3) that extended to the nasopharynx. A left exophthalmia was noted. No cervical lymph nodes were found. The ocular motility and the fundus examination were normal. MRI was performed and showed a mass of the left maxillary sinus which was isointense on both T1 and T2-weighted sequences. Extension to the nasal cavity, nasopharynx and left orbit was objectified. Tumor was removed by paralateronasal approach. Post-operative radiotherapy was planned. Unfortunately, orbital, and cutaneous recurrence occurred. Thus, palliative radiotherapy was achieved.

\section{Discussion and Conclusion}

Sinonasal tract malignancies are rare tumors that account for $3 \%$ to $5 \%$ of all the upper aerodigestive tract cancers [4]. Among these malignancies, ACC is the most frequent salivary gland cancer. It represents $10 \%$ of all malignancies at this site $[5,6]$ and about $10 \%$ to $25 \%$ of all ACCs of the head and neck [7]. It is a slow-growing and locally aggressive tumor with clinical, biological, and therapeutic characteristics. Mean age at diagnosis is 55 to 57-year-old [8]. ACC is thought to be hormonally dependent. A female predominance was noted in literature [9]. Tumor growth is insidious thus, patients are asymptomatic for a long period and may present with advanced-stage disease [3] . ACC is also characterized by a tendency for perineural spread along major and minor nerves which makes the treatment challenging [10]. Most frequent signs are nasal obstruction, epistaxis, nasal discharge, facial pain and dysosmia [6] likewise our patients. This unspecific presentation leads generally to a delayed diagnosis. When the tumor reaches large dimensions and invades surrounding bone and structures, severe signs appear such as headaches, seizures, ophthalmoplegia, diplopia and trigeminal neuralgia [6,8]. The occurrence of neurological and ophthalmological signs is correlated with poor prognosis [3]. The maxillary sinus is the most common site followed by the nasal cavity and the ethmoid sinus $[8,11]$. The frontal and sphenoid sinuses are correlated with a worse survival rates due to their proximity to the skull base [7]. Skull base involvement and intracranial extension are remarkably high. Cervical lymph node metastases are rarely reported. They accounted for $6 \%$ in the series of Rhee [11], 3.6\% in the series of Unsal [7] and none of our patients. Lymph node involvement is correlated with poor prognosis as they represent a risk factor for distant metastasis and low survival rate [12].

Histologically, ACC is composed of three subtypes: tubular, cribriform, and solid [7]. The cribriform subtype is the most common one whereas the solid subtype has the worst prognosis [11]. Treatment of sinonasal ACC is based on surgery, followed by radiotherapy [13]. According to Lupinetti et al., overall, and disease-specific survival are improved when patients are treated with surgery and postoperative radiation compared with other treatment modalities [6]. The aim of surgery is to ensure complete tumor removal with negative margins. However, surgery of advanced stages tumor is challenging and can result in serious morbidity, especially when critical anatomic structures are involved such as the brain, the orbit, the cranial nerves, and the nasopharynx [10]. In our series, tumor extended to the nasopharynx and orbit in one patient. ACC is a radiosensitive tumor but not radio curable [13]. Postoperative radiotherapy aims to clear positive margins left after surgery [14]. Long-term survival does not seem to be improved when radiotherapy is associated, but 5-year diseasefree period is slightly prolonged [7]. In the study of Rhee, the 5-year local recurrence rate was $42 \%$ in $\mathrm{T} 3$ and $\mathrm{T} 4$ stages despite postoperative radiotherapy was performed in most of the patients [11]. Radiation therapy alone is indicated in T4 unresectable tumors [15]. Chemotherapy has not proven effectiveness in ACC treatment. Further clinical trials using combined therapeutic approaches are required [11]. ACC is characterized by local recurrence and distant metastasis that can occur several years after initial treatment and remission [11]. In the series of Miller, local failure rate was $50 \%$. This high rate was explained by the high proportion of patients diagnosed in advanced stages [10]. In other studies, treatment failure rates range from $60 \%$ to $70 \%$ [15]. ACC of sinonasal tract has a poor prognosis. The most relevant prognosis factors are tumor site, skull base invasion, stage, histopathologic type, and treatment modalities. Treatment is based on surgery. Even though ACC is not 
radio curable, post-operative radiotherapy improves locoregional control. Early diagnosis, applying the appropriate therapeutic approach and long-term follow-up are the mean guarantees to improve prognosis.

\section{Funding and Conflict of Interest}

Authors declare that they have not receive any financial support. No conflict of interest.

\section{References}

1. Duberge T, Benezery K, Resbeut M, Azria D, Minsat M, et al. (2012) Adenoid cystic carcinoma of the head and neck: a retrospective series of 169 cases. Cancer Radiother 16(4): 247-256.

2. da Cruz Perez DE, Pires FR, Lopes MA, de Almeida OP, Kowalski LP (2006) Adenoid cystic carcinoma and mucoepidermoid carcinoma of the maxillary sinus: report of a 44-year experience of 25 cases from a single institution. J Oral Maxillofac Surg 64(11): 1592-1597.

3. Andrade MF, de Faria PR, Cardoso SV, Santos MR, Dias FL, et al. (2014) Adenoid cystic carcinoma of the maxillary sinus: a clinical-pathological report of 10 years of experience from a single institution. Int J Oral Maxillofac Surg 43(11): 1313-1318.

4. Banuchi V, Mallen J, Kraus D (2015) Cancers of the nose, sinus, and skull base. Surg Oncol Clin N Am 24(3): 563-577.

5. Kokemueller H, Eckardt A, Brachvogel P, Hausamen JE (2004) Adenoid cystic carcinoma of the head and neck--a 20 years' experience. Int J Oral Maxillofac Surg 33(1): 25-31.

6. Lupinetti AD, Roberts DB, Williams MD, Kupferman ME, Rosenthal DI, et al. (2007) Sinonasal adenoid cystic carcinoma: The MD Anderson Cancer Center experience. Cancer 110(12): 2726-2731.
7. Unsal AA, Chung SY, Zhou AH, Baredes S, Eloy JA (2017) Sinonasal adenoid cystic carcinoma: a population-based analysis of 694 cases. Int Forum Allergy Rhinol 7(3): 312-320.

8. Husain Q Kanumuri VV, Svider PF, Radvansky BM, Boghani Z, et al. (2013) Sinonasal adenoid cystic carcinoma: systematic review of survival and treatment strategies. Otolaryngol Head Neck Surg 148(1): 29-39.

9. Turner JH, Reh DD (2012) Incidence and survival in patients with sinonasal cancer: a historical analysis of population-based data. Head Neck 34(6): 877-885.

10. Miller ED, Blakaj DM, Swanson BJ, Xiao W, Gillison ML, et al. (2017) Sinonasal adenoid cystic carcinoma: Treatment outcomes and association with human papillomavirus. Head Neck 39(7): 1405-1411.

11. Rhee CS, Won TB, Lee CH, Min YG, Sung MW, et al. (2006) Adenoid cystic carcinoma of the sinonasal tract: treatment results. Laryngoscope 116(6): 982-986.

12. Spiro RH (1997) Distant metastasis in adenoid cystic carcinoma of salivary origin. Am J Surg 174(5): 495-498.

13. Wiseman SM, Popat SR, Rigual NR, Hicks WL Jr, Orner JB, et al. (2002) Adenoid cystic carcinoma of the paranasal sinuses or nasal cavity: a 40year review of 35 cases. Ear Nose Throat J 81(8): 510-514, 516-517.

14. Garden AS, Weber RS, Morrison WH, Ang KK, Peters LJ (1995) The influence of positive margins and nerve invasion in adenoid cystic carcinoma of the head and neck treated with surgery and radiation. Int J Radiat Oncol Biol Phys 32(3): 619-626.

15. Bhattacharyya N (2003) Factors affecting survival in maxillary sinus cancer. J Oral Maxillofac Surg 61(9): 1016-1021.
To Submit Your Article Click Here:

This work is licensed under Creative Commons Attribution 4.0 License

Submit Article
DOI: $10.32474 /$ SJ0.2020.05.000206

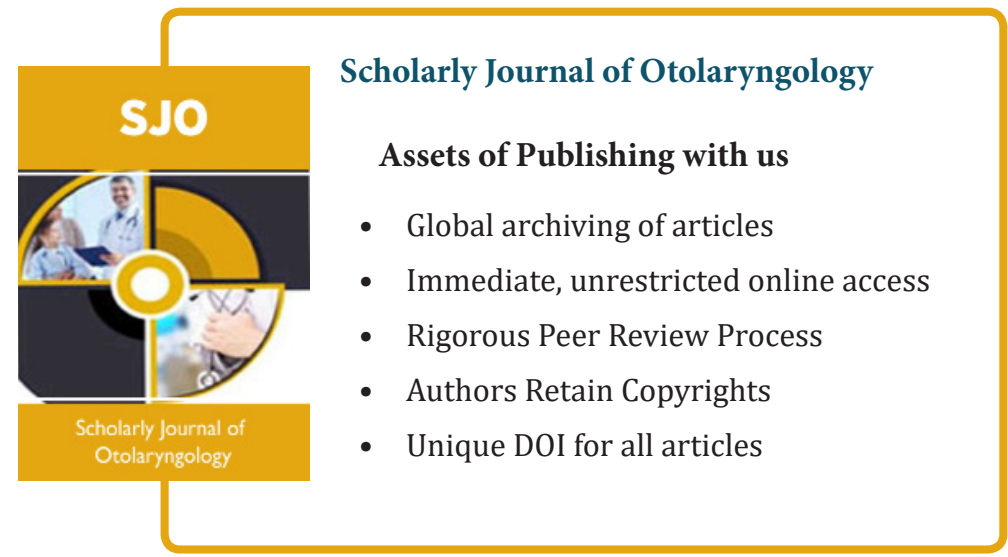

